\title{
Re-Programming Hydrogel Properties using a Fuel-driven Reaction Cycle
}

\author{
Nishant Singh*, Bruno Lainer, Georges J. M. Formon, Serena De Piccoli, and Thomas M. Hermans* \\ Université de Strasbourg, \\ CNRS, ISIS, 8 allée Gaspard Monge, \\ 67000 Strasbourg, France.
}

Supporting Information available.

\begin{abstract}
Nature uses catalysis as an indispensable tool to control assembly and reaction cycles in vital non-equilibrium supramolecular processes. For instance, enzymatic methionine oxidation regulates actin (dis)assembly, and catalytic guanosine triphosphate hydrolysis is found in tubulin (dis)assembly. Here we present a completely artificial reaction cycle which is driven by a chemical fuel that is catalytically obtained from a 'pre-fuel'. The reaction cycle controls the disassembly and re-assembly of a hydrogel, where the rate of pre-fuel turnover dictates the morphology as well as the mechanical properties. By adding additional fresh aliquots of fuel and removing waste, the hydrogels can be re-programmed time after time. Overall, we show how catalysis can control fuel generation to control reaction / assembly kinetics and materials properties in life-like nonequilibrium systems.
\end{abstract}

Nature employs supramolecular structures away from the thermodynamic equilibrium for several vital functions such as immune response, transcription, motility, and cell division. ${ }^{1,2}$ Examples include actin filaments, ${ }^{3}$ microtubules, ${ }^{4}$ and muscle fibers ${ }^{5}$, which can modulate their structures and dynamics in response to subtle changes in signals or chemical fuels. ${ }^{6,7}$ In these natural systems, catalysis is used to tune rates of assembly and disassembly. ${ }^{8}$ For instance, after actin activation a redox enzyme (Mical) responds to extracellular cues to directly catalyze the oxidation of methionine residues on actin filaments to trigger dissassembly. ${ }^{9}$ Similarly, processes like cell division and motility rely on catalytic guanosine triphosphate hydrolysis to control microtubule (dis)assembly. ${ }^{10}$ Likewise, inflammasomes form micron sized specs responsible for frontline immune response where the (dis)assembly is catalyzed by ligand-acceptor interactions. ${ }^{11}$

Similar to nature, fuel driven reaction cycles have been used to create non-equilibrium self-assemblies. ${ }^{12-25}$ Few studies have shown the use of biological ${ }^{26}$ and synthetic ${ }^{27}$ catalysts to control supramolecular order and properties in assemblies but at equilibrium. For non-equilibrium systems, catalysts can be used to program the (pre-)fuel release and activity beforehand for precise kinetic control. Although enzymes have been used for this purpose, ${ }^{21-23,25,28-31}$ examples of synthetic non-equilibrium systems with catalytic control are scarce. ${ }^{19,32}$ This is because implementing catalysts for fuel generation in reaction cycles for (de)activation of building blocks is very challenging. It demands careful study of the kinetics of the coupled reactions, and the resulting (dis)assembly processes while keeping the catalyst(s) active for the required time periods.

Here we present a reaction cycle driven by catalytic production of fuels to achieve transient disassembly of a hydrogelator (i.e., gelsol-gel). We can control the production of one of the fuels by catalytically converting a pre-fuel. The materials properties after each transient gel-sol-gel cycle depend on the catalytic rates of fuel production and in some cases leads to different gel morphology and molecular packing. By utilizing the sponge-like 'syneresis' behavior of the hydrogels we can mechanically squeeze out the waste and re-fuel the system to achieve up to thirteen such transient cycles (gel-sol-gel) with minimal loss in materials properties.

The catalytic reaction cycle involves a previously reported aldehyde saccharide hydrogelator ${ }^{33}$ (SachCHO in Figure 1a). Upon addition of dithionite (DT), the aldehyde moiety of SachCHO is quantitatively converted to an $\alpha$-hydroxy sulfonate $\left(\mathrm{SachSO}_{3}{ }^{-}\right)$. In our case, we operate at $25{ }^{\circ} \mathrm{C}$ (vs. temperatures $\geq 80{ }^{\circ} \mathrm{C}$ for the reported cases ${ }^{34}$ ) and therefore $\mathrm{SachSO}_{3}^{-}$does not reduce to the corresponding alcohol, but is stable. Macroscopically, SachCHO gels rapidly disassemble upon addition of DT due to electrostatic repulsion to give a clear solution in 15-20 minutes (Figure 1a). To achieve re-gelation we produce formaldehyde in situ, which consumes $\mathrm{SachSO}_{3}^{-}$and recovers the original SachCHO molecule. The onset of re-gelation can be tuned by acid catalysismediated by glucono-delta-lactone (GdL) hydrolysis - to convert pre-fuel hexamethylenetetramine (HMTA) into formaldehyde (fuel) and ammonia (Figure 1a). Hence, adding the fuel system (i.e., DT, GdL, and HMTA) to the SachCHO hydrogel at time zero gives an autonomously running chemically fueled transient cycle performing a gel-sol-gel transition (Figure 1a, SI video 1).

We found that the thermally annealed SachCHO assembly is highly cooperative, evidenced by the $20 \mathrm{~K}$ hysteresis (Figure 1b). When assembly is induced chemically (i.e, $\mathrm{SachSO}_{3}{ }^{-}$to SachCHO conversion upon addition of formaldehyde) instead of thermally, again the assembly is very cooperative (see S-shaped curves in Figure 1c and 1d). The latter experiments fit well to a kinetic model including secondary nucleation ${ }^{35,36}$ (Figure 1c, Figure S1, see SI for more details), which indicates that nucleation is followed by much faster elongation $\left(\sim 10^{8}\right.$ times higher rate) and subsequent secondary nucleation (i.e., growth of fibers from existing assemblies). 
a)

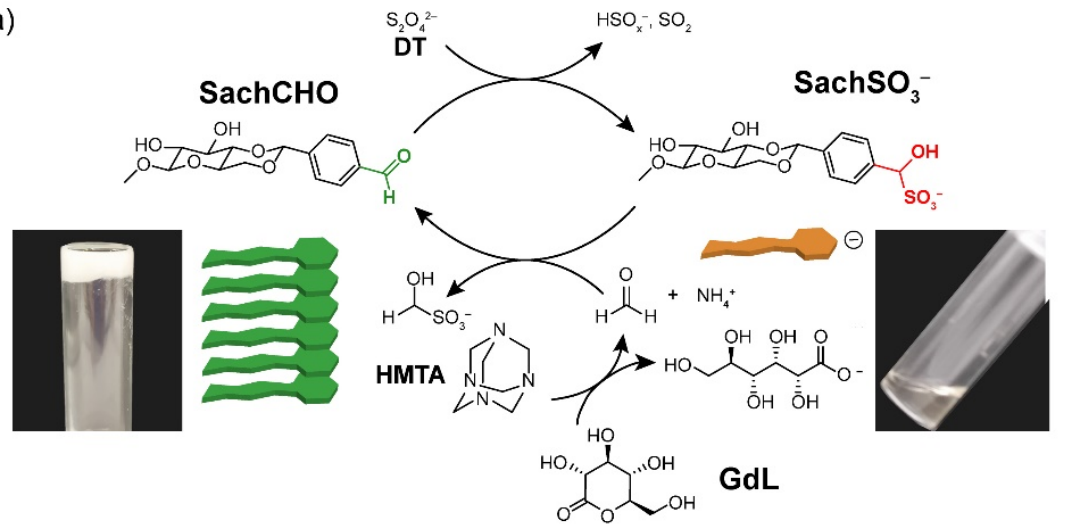

c)

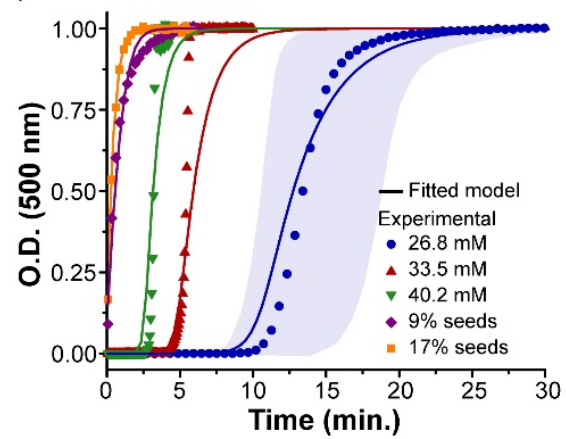

d)

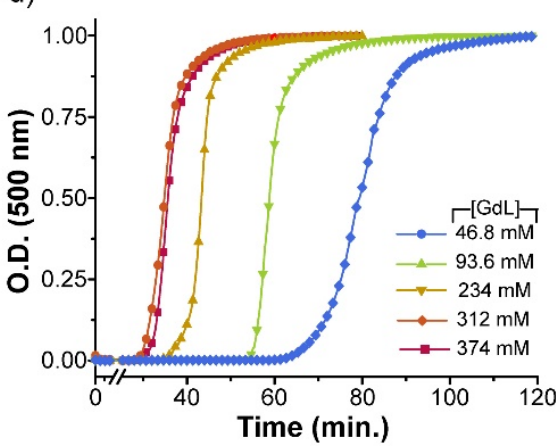

b)

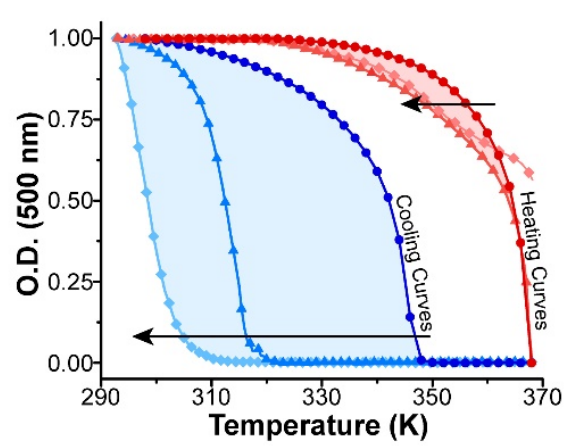

e)

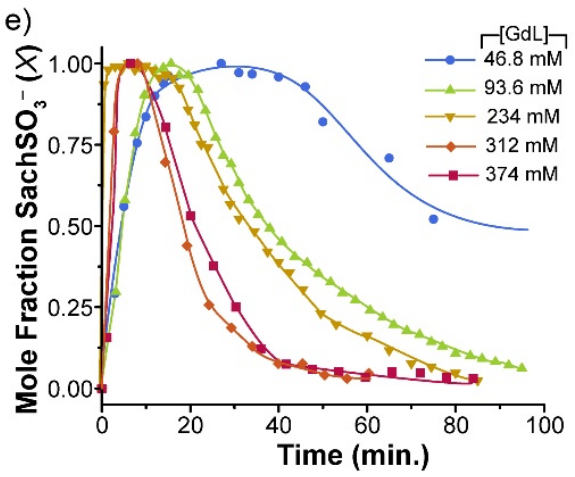

Figure 1. (a) Scheme of the chemically fueled reaction cycle for transient disassembly by dithionite DT of SachCHO hydrogelator followed by in situ catalytic formation of formaldehyde by glucono- $\delta$-lactone GdL and hexamethylenetetramine HMTA, leading to regelation. (b) Heat-cool cycles at different rates for thermally annealed gel using UV-Vis turbidity measurements, where the optical density (O.D.) at $500 \mathrm{~nm}$ is measured. 70 degree, 50 degree and 20 degree hysteresis for heat $/$ cool rate $10 \mathrm{~K} / \mathrm{min}(\diamond), 1 \mathrm{~K} / \mathrm{min}(\boldsymbol{\Delta})$, and $5 \mathrm{~min}$ hold at each temperature (•), respectively. Arrows represent increasing heating/cooling rate. (c) Global fitting of (un)seeded gelation (SachSO ${ }_{3}^{-}$ to SachCHO) using excess HCHO followed using O.D. at $500 \mathrm{~nm}$ (see main text). Legend shows initial [SachSO $\left.{ }_{3}\right]$. The faded blue region delineates the upper / lower boundaries of triplicate experiments. (d) O.D. at $500 \mathrm{~nm}$ for $\mathrm{SachSO}_{3}{ }^{-}$solution to SachCHO gel, catalyzed at different [GdL]. Lines to guide the eye. (e) Evolution of $\mathrm{SachSO}_{3}^{-}$in the transient cycles as seen by NMR. Lines to guide eye. Initial thermal gel with $[\mathrm{SachCHO}]=54 \mathrm{mM}$, and $[\mathrm{HMTA}]=190 \mathrm{mM},[\mathrm{DT}]=191 \mathrm{mM}$ in chemically fueled transient cycles.

A more direct method to show that secondary nucleation plays a role in the assembly process comes from confocal microscopy, where monomers were observed to grow from existing SachCHO fibers (Figure S2).

In the chemically fueled transient cycles as described before, UVVis turbidity experiments (following optical density O.D. at 500 $\mathrm{nm}$ ) show the influence of [GdL] on $\mathrm{SachSO}_{3}{ }^{-}$to SachCHO conversion rates (Figure 1d and Figure S3). Early onset of nucleation and faster elongation rates corresponding to low solution lifetimes are seen with increasing [GdL]. Following the kinetics with $\mathrm{NMR}$, we can confirm the increased rate of $\mathrm{SachSO}_{3}{ }^{-}$to SachCHO conversion for higher [GdL] (Figure 1e). The back conversion of $\mathrm{SachSO}_{3}{ }^{-}$to $\mathrm{SachCHO}$ happens in $\sim 75$ minutes for $[\mathrm{GdL}]=93.6 \mathrm{mM}$, and progressively decreases up to $312 \mathrm{mM}$. Increasing [GdL] to $374 \mathrm{mM}$ shows no further rate enhancement (Figure S4). This plateauing effect is also seen in turbidity measurements where $[\mathrm{GdL}]=374 \mathrm{mM}$ shows no increased kinetics as compared to $312 \mathrm{mM}$ (Figure 1d and Figure S3). This is because for $[\mathrm{GdL}]=312 \mathrm{mM}$ and $374 \mathrm{mM}$ the initial $\mathrm{pH}$ drop is the same (from 8.0 to $\sim 5.1$ ), which limits the acid catalyzed HMTA to HCHO conversion (Figure S5).

Next, we studied the impact of the catalysis rates on the supramolecular polymerization of SachCHO and resultant materials properties. As a starting point of the cycles, we used thermally annealed gels consisting of long crystalline fibers of hundreds of micrometers in length (Figure 2a, b). Upon addition of fuels to such a gel we can observe rapid dissolution of these fibers (not shown). In transient cycles with [GdL] $=234 \mathrm{mM}$ we observe the formation of sparsely distributed star-like structures consisting of broad fibers with undulating edges (Figure 2c, d). Use of high $[\mathrm{GdL}]=374 \mathrm{mM}$ results in faster formation of heavily branched, thinner and longer fibres originating from a central nucleation site (Figure 2e, f. SI video 2).

The catalysis driven self-assembly pathways clearly play a role in the final morphologies and molecular packing of the selfassembled structures (as observed by others ${ }^{37,38}$ ). 

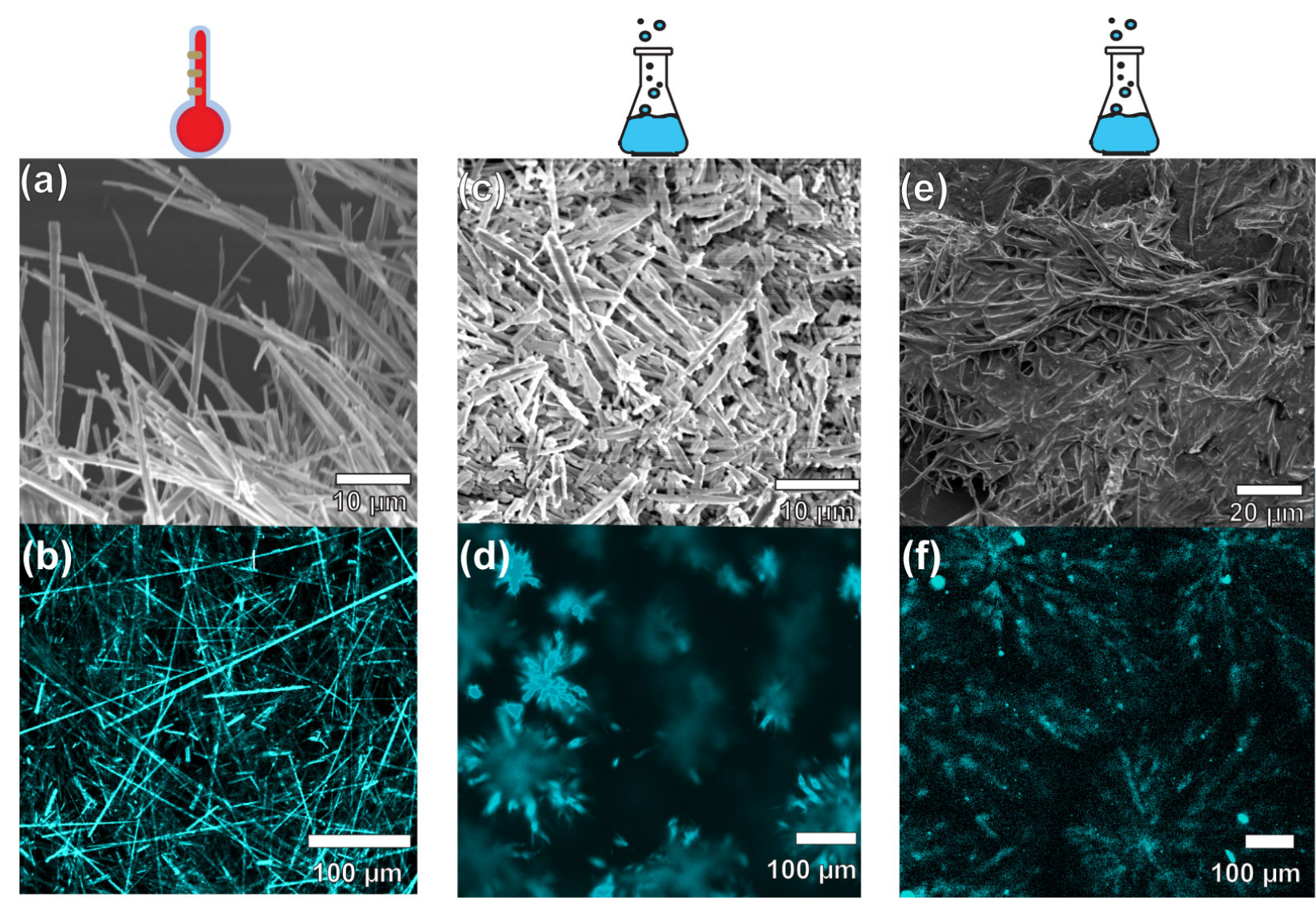

Figure 2. Effect of the self-assembly pathway on final morphologies as oserved by Scanning Electron Microscopy (a, c, e) and Confocal Microscopy (b, d, f: scale bar $=100 \mu \mathrm{m})$ micrographs. (a and b): crystalline long fibers $(500-800 \mu \mathrm{m})$ of $\sim 1 \mu \mathrm{m}$ width formed in thermally annealed gel, (c and d): flower like assemblies composed of short $(60-100 \mu \mathrm{m})$ and broad fibers $(2-5 \mu \mathrm{m})$ formed during slow catalyzed $([\mathrm{GdL}]=234 \mathrm{mM})$ formation of SachCHO during a transient cycle, (e and f): fractal-like assemblies composed of long branched fibers 1$2 \mu \mathrm{m}$ wide and $\geq 200 \mu \mathrm{m}$ long, formed during fast catalyzed ( $[\mathrm{GdL}]=374 \mathrm{mM}$ ) formation of SachCHO during a transient cycle. $[\mathrm{SachCHO}]=54 \mathrm{mM}$ in all the cases, and $[\mathrm{HMTA}]=190 \mathrm{mM}$, [DT] $=191 \mathrm{mM}]$ in chemically fueled transient cycles.

Powder XRD (X-ray diffraction) patterns of the freeze-dried hydrogels showed no significant difference between thermally annealed and chemically fueled gels of $93.6 \mathrm{mM}$ and $234 \mathrm{mM}$ GdL concentrations. The main peaks at $1.15 \mathrm{~nm}$ and $0.648 \mathrm{~nm}$ are likely inter-columnar distances and $0.38 \mathrm{~nm}$ for intermolecular stacking distance within the columns. ${ }^{27}$ However, the chemically fueled gel using $[\mathrm{GdL}]=374 \mathrm{mM}$ shows two new reflections at $0.325 \mathrm{~nm}$ and $0.305 \mathrm{~nm}$ indicative of closer intermolecular packing distances within a column (Figure S6).

On a macroscopic scale, rheology experiments show that varying [GdL] for a transient cycle not only affects the gelation time, but also re-programs the original thermally annealed hydrogel $\left(\mathrm{G}^{\prime}=\right.$ $800 \mathrm{~Pa}$ ) to varying stiffness (Figure 3a, Figure S7). The storage moduli of chemically fueled gels can vary from $\sim 110 \mathrm{~Pa}$ for $[\mathrm{GdL}]=46.8 \mathrm{mM}$ to $\sim 2100 \mathrm{~Pa}$ for $[\mathrm{GdL}]=374 \mathrm{mM}$, clearly dependent on the GdL-driven catalytic turnover. Taken together with the microscopy and XRD data, we find that higher catalytic rates give longer and more branched fiber networks with closer intermolecular packings, resulting in stronger hydrogels. Beyond a given GdL concentration $(374 \mathrm{mM})$ no further increase in the stiffness of the re-programmed gel $\left(\mathrm{G}^{\prime}=\sim 2100 \mathrm{~Pa}\right)$ is observed. This can be due to the accumulated waste hindering the selfassembly or a result of plateauing effect after a certain [GdL] as seen in UV and NMR before (cf. Figure 1d and e).

Up to here, we have shown reversible gel-sol-gel transitions. Thus, this should also permit to perform multiple fueled reaction cycles and re-program the hydrogels time after time. For this purpose, we refuel an already chemically formed hydrogel $\left(\mathrm{G}^{\prime}=\right.$ $1100 \mathrm{~Pa}$ ) using different [GdL]. The second fueled cycle again resets the hydrogel to varying stiffness depending on the [GdL] used (' 2 nd cycle' in Figure 3a). This shows that control over the gel properties can be obtained also in subsequent cycles. A notorious challenge in synthetic systems, however, is waste accumulation after many cycles. In this regard, the SachCHO hydrogel has an interesting property of expelling solvent under mechanical pressure called 'syneresis'. ${ }^{39}$ Since all fuels / waste are water soluble, syneresis can be used to remove them after each transient cycle. For this purpose, a syringe and a needle filled with a cotton swab was used (Figure 3b). First, a chemically fueled gel was formed inside the syringe, after which pressure was (manually) applied onto the plunger to remove most of the solvent (including waste products). Next, a solution containing fresh fuels was aspirated into the syringe leading to re-solubilization and shortly after, re-gelation. Repeating the latter two steps, up to 13 cycles could be achieved with only minimal changes in gelation kinetics (Figure 3c and Figure S8, S9).

We have presented a completely synthetic system where the reaction cycle driving the (dis)assembly pathways has an in-built catalytic process for fuel generation from a pre-fuel. The rate of fuel generation controls the rate of (re-)assembly and dictates the lifetime of the disassembled solution state. Overall, our approach yields hydrogels where the morphology and materials properties can be controlled, and can be re-programmed time after time. 
Ideally, future systems would achieve catalytic control over both the fuel used in the assembly as well as in the disassembly pathway. This will impart much needed control over all the steps involved in dissipative self-assembly and help create purely synthetic life-like systems with control similar to that found in living materials.
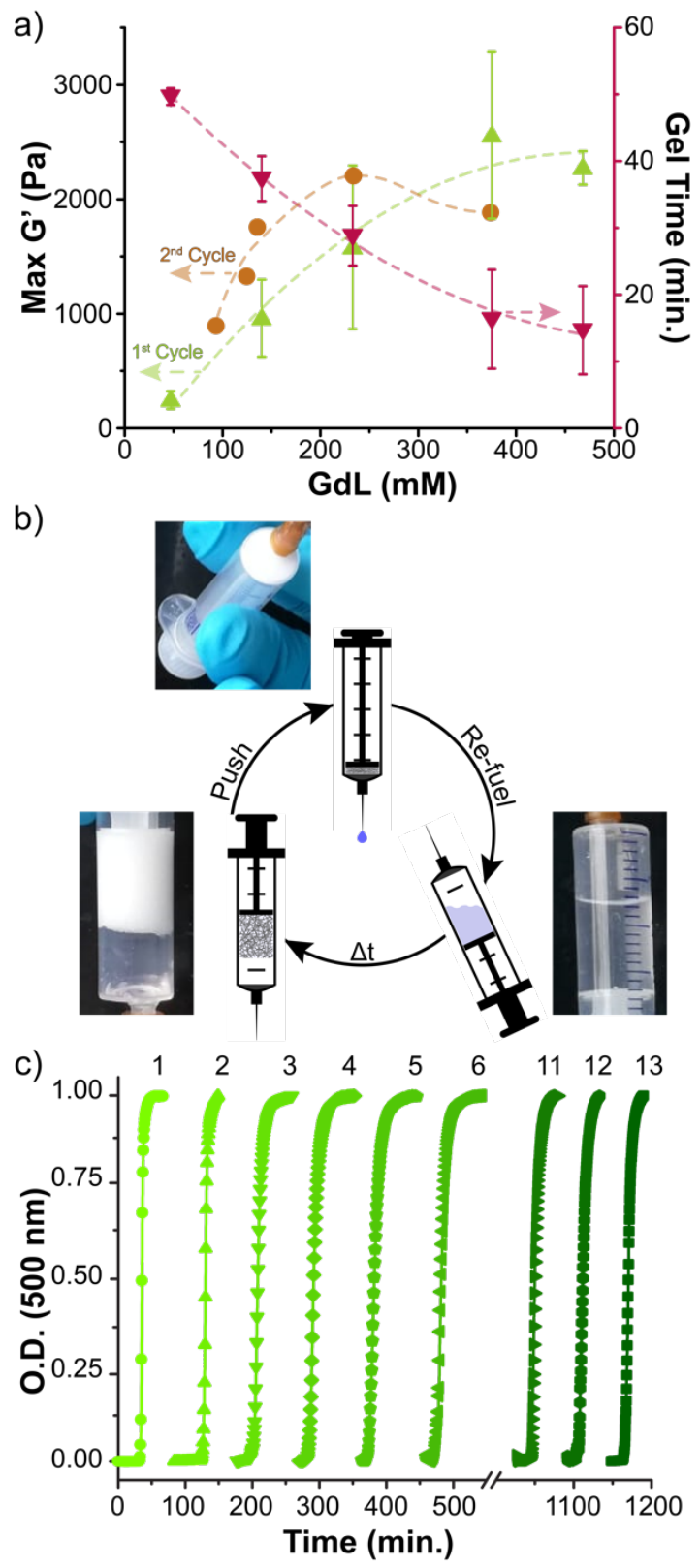

Figure 3. Rheology and syneresis experiments. (a) Rheology showing a trend of decreasing gelation time $(\boldsymbol{\nabla})$ and increasing stiffness $\left(\mathrm{G}^{\prime}-\triangle\right)$ with increasing $[\mathrm{GdL}]$ for solution to gel transition in the transient cycles. [HMTA] $=190 \mathrm{mM}$, [DT] $=191 \mathrm{mM}$, $[$ SachCHO] $=54 \mathrm{mM}$. Resetting of hydrogels after the first cycle $([$ HMTA $]=95 \mathrm{mM},[\mathrm{DT}]=96 \mathrm{mM},[\mathrm{GdL}]=93.6 \mathrm{mM}$, $[\mathrm{SachCHO}]=54 \mathrm{mM}$ ) by second round of fuels addition $([$ HMTA $]=190 \mathrm{mM},[\mathrm{DT}]=96 \mathrm{mM})$ with similar $[\mathrm{GdL}]-$ depended stiffness trend $(\bullet)$ (dashed lines are to guide the eye.). Error bars show standard deviations over three independent experiments, whereas circles depict single measurements. (b) In clockwise direction, chemically fueled gel made in a syringe (bottom left), fiber network remains in the syringe after solvent expulsion by pushing the plunger (top), dissolution of fibers after refueling (bottom right), and re-formation of gel after a defined time. $([\mathrm{DT}]=121 \mathrm{mM},[\mathrm{HMTA}]=190 \mathrm{mM},[\mathrm{GdL}]=312 \mathrm{mM})$. Note: SachCHO molecules in solution also are extruded along with the waste products during syneresis, so $5.3 \mathrm{mM}$ SachCHO was added along with the fuels after each extrusion to correct the amount of building blocks. (c) O.D. at $500 \mathrm{~nm}$ showing similar nucleation-elongation kinetics for 13 cycles performed by refueling after waste removal.

\section{ASSOCIATED CONTENT}

\section{Supporting Information}

The Supporting Information is available free of charge. Materials, methods, synthesis, characterization, additional data, modelling information.

\section{AUTHOR INFORMATION}

\section{Corresponding Author}

* hermans@unistra.fr; nishant.singh@unistra.fr

Notes

The authors declare no competing financial interests.

\section{ACKNOWLEDGMENT}

T.M.H., N.S. and S.D.P. would like to acknowledge funding from ERC-2017-STG "Life-Cycle" (757910), G.J.M.F. received funding from Ministère de l'Education Nationale de l'Enseignement supérieur et de la Recherche. B.L. received funding by the French National Research Agency (ANR) through the Programme d'Investissement d'Avenir under contract 17-EURE-0016.

\section{REFERENCES}

(1) Kushner, D. J. Self-Assembly of Biological Structures. Bacteriol. Rev. 1969, 33 (2), 302-345.

(2) Feng, Z.; Zhang, T.; Wang, H.; Xu, B. Supramolecular Catalysis and Dynamic Assemblies for Medicine. Chem. Soc. Rev. 2017, $46(21), 6470-6479$.

Pieters, B. J. G. E.; Van Eldijk, M. B.; Nolte, R. J. M.; Mecinović, J. Natural Supramolecular Protein Assemblies. Chem. Soc. Rev. 2016, 24-39.

Valiron, O.; Caudron, N.; Job, D. Microtubule Dynamics. Cell. Mol. Life Sci. 2001, 58, 2069-2084.

Krans, J. L. The Sliding Filament Theory of Muscle Contraction. Nat. Educ. 2010, 3 (9), 66

(6) Fletcher, D. A.; Mullins, R. D. Cell Mechanics and the Cytoskeleton. Nature. January 2010, pp 485-492.

(7) Alberts, B.; Johnson, A.; Lewis, J.; Raff, M.; Roberts, K. Walter, P. Molecular Biology of the Cell, 4 th.; Garland Science, Ed.; New York, 2002.

(11) Lu, A.; Wu, H. Structural Mechanisms of Inflammasome Assembly. FEBS J. 2015, 282 (3), 435-444.

(12) Boekhoven, J.; Brizard, A. M.; Kowlgi, K. N. K.; Koper, G. J. M.; Eelkema, R.; Van Esch, J. H. Dissipative Self-Assembly of a Molecular Gelator by Using a Chemical Fuel. Angew. Chemie - Int. Ed. 2010, 49 (28), 4825-4828.

(13) Dambenieks, A. K.; Vu, P. H. Q.; Fyles, T. M. Dissipative Assembly of a Membrane Transport System. Chem. Sci. 2014, 5 (9), 3396-3403.

(14) Leira-Iglesias, J.; Tassoni, A.; Adachi, T.; Stich, M.; Hermans, T. M. Oscillations, Travelling Fronts and Patterns in a Supramolecular System. Nat. Nanotechnol. 2018, 13 10211028. 

Dissipative Self-Assembly That Exploits Cooperative Catalysis. Angew. Chemie Int. Ed. 2019, 58 (1), 244-247.

(16) Agarwal, S.; Franco, E. Enzyme-Driven Assembly and Disassembly of Hybrid DNA-RNA Nanotubes. J. Am. Chem. Soc. 2019, 141 (19), 7831-7841.

(17) De, S.; Klajn, R. Dissipative Self-Assembly Driven by the Consumption of Chemical Fuels. Adv. Mater. 2018, 30 (41), 16.

(18) Boekhoven, J.; Hendriksen, W. E.; Koper, G. J. M.; Eelkema, R.; Van Esch, J. H. Transient Assembly of Active Materials Fueled by a Chemical Reaction. Science 2015, 349 (6252), 1075-1079.

(19) Wood, C. S.; Browne, C.; Wood, D. M.; Nitschke, J. R. FuelControlled Reassembly of Metal-Organic Architectures. ACS Cent. Sci. 2015, 1 (9), 504-509.

(20) Heuser, T.; Steppert, A. K.; Molano Lopez, C.; Zhu, B.; Walther, A. Generic Concept to Program the Time Domain of Self-Assemblies with a Self-Regulation Mechanism. Nano Lett. 2015, 15 (4), 2213-2219.

(21) Pappas, C. G.; Sasselli, I. R.; Ulijn, R. V. Biocatalytic Pathway Selection in Transient Tripeptide Nanostructures. Angew. Chemie Int. Ed. 2015, 54 (28), 8119-8123.

(22) Maiti, S.; Fortunati, I.; Ferrante, C.; Scrimin, P.; Prins, L. J. Dissipative Self-Assembly of Vesicular Nanoreactors. Nat. Chem. 2016, 8 (7), 725-731.

(23) Sorrenti, A.; Leira-Iglesias, J.; Sato, A.; Hermans, T. M. NonEquilibrium Steady States in Supramolecular Polymerization. Nat. Commun. 2017, 8, 15899.

(24) Tena-Solsona, M.; Rieß, B.; Grötsch, R. K.; Löhrer, F. C.; Wanzke, C.; Käsdorf, B.; Bausch, A. R.; Müller-Buschbaum, P.; Lieleg, O.; Boekhoven, J. Non-Equilibrium Dissipative Supramolecular Materials with a Tunable Lifetime. Nat. Commun. 2017, 8, 15895.

(25) Mishra, A.; Korlepara, D. B.; Kumar, M.; Jain, A.; Jonnalagadda, N.; Bejagam, K. K.; Balasubramanian, S.; George, S. J. Biomimetic Temporal Self-Assembly via FuelDriven Controlled Supramolecular Polymerization. Nat. Commun. 2018, 9 (1), 1-9.

(26) Hirst, A. R.; Roy, S.; Arora, M.; Das, A. K.; Hodson, N.; Murray, P.; Marshall, S.; Javid, N.; Sefcik, J.; Boekhoven, J.; Van Esch, J. H.; Santabarbara, S.; Hunt, N. T.; Uljin, R. V. Biocatalytic Induction of Supramolecular Order. Nat. Chem. 2010, 2 (12), 1089-1094.

(27) Boekhoven, J.; Poolman, J. M.; Maity, C.; Li, F.; Van Der Mee, L.; Minkenberg, C. B.; Mendes, E.; Van Esch, J. H.; Eelkema, R. Catalytic Control over Supramolecular Gel Formation. Nat. Chem. 2013, 5 (5), 433-437.

(28) Heuser, T.; Weyandt, E.; Walther, A. Biocatalytic FeedbackDriven Temporal Programming of Self-Regulating Peptide Hydrogels. Angew. Chemie Int. Ed. 2015, 54 (45), 1325813262.

(29) Pappas, C. G.; Shafi, R.; Sasselli, I. R.; Siccardi, H.; Wang, T.; Narang, V.; Abzalimov, R.; Wijerathne, N.; Ulijn, R. V. Dynamic Peptide Libraries for the Discovery of Supramolecular Nanomaterials. Nat. Nanotechnol. 2016, 11 (11), 960-967.

(30) Heinen, L.; Heuser, T.; Steinschulte, A.; Walther, A. Antagonistic Enzymes in a Biocatalytic Ph Feedback System Program Autonomous DNA Hydrogel Life Cycles. Nano Lett. 2017, 17 (8), 4989-4995.

(31) Jain, A.; Dhiman, S.; Dhayani, A.; Vemula, P. K.; George, S. J. Chemical Fuel-Driven Living and Transient Supramolecular Polymerization. Nat. Commun. 2019, 10 (1), 1-9.

(32) Colomer, I.; Morrow, S. M.; Fletcher, S. P. A Transient SelfAssembling Self-Replicator. Nat. Commun. 2018, 9 (1), 1-6.

(33) Chen, Q.; Lv, Y.; Zhang, D.; Zhang, G.; Liu, C.; Zhu, D. Cysteine and PH-Responsive Hydrogel Based on a Saccharide Derivative with an Aldehyde Group. Langmuir 2010, 26 (5), 3165-3168.

(34) de Vries, J. G.; Kellogg, R. M. Reduction of Aldehydes and Ketones by Sodium Dithionite. J. Org. Chem. 1980, 45 (21), 4126-4129.

(35) Cohen, S. I. A.; Vendruscolo, M.; Dobson, C. M.; Knowles, T. P. J. Nucleated Polymerization with Secondary Pathways. II. Determination of Self-Consistent Solutions to Growth Processes Described by Non-Linear Master Equations. J. Chem. Phys.
2011, 135 (6)

Meisl, G.; Kirkegaard, J. B.; Arosio, P.; Michaels, T. C. T.; Vendruscolo, M.; Dobson, C. M.; Linse, S.; Knowles, T. P. J. Molecular Mechanisms of Protein Aggregation from Global Fitting of Kinetic Models. Nat. Protoc. 2016, 11 (2), 252-272.

(37) Korevaar, P. A.; George, S. J.; Markvoort, A. J.; Smulders, M. M. J.; Hilbers, P. A. J.; Schenning, A. P. H. J.; De Greef, T. F. A.; Meijer, E. W. Pathway Complexity in Supramolecular Polymerization. Nature 2012, 481 (7382), 492-496.

(38) Grötsch, R. K.; Wanzke, C.; Speckbacher, M.; Angl, A.; Rieger, B.; Boekhoven, J. Pathway Dependence in the Fuel-Driven Dissipative Self-Assembly of Nanoparticles. J. Am. Chem. Soc. 2019, 141 (25), 9872-9878.

(39) Conte, M. P.; Singh, N.; Sasselli, I. R.; Escuder, B.; Ulijn, R. V. Metastable Hydrogels from Aromatic Dipeptides. Chem. Commun. 2016, 52 (96), 13889-13892. 


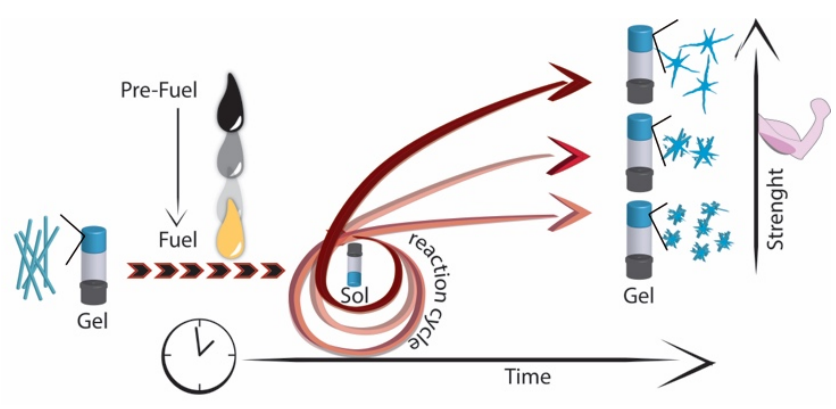

